\title{
Prehistoric Greek phonological chronology, with some reflections on sibilance, aspiration, and spirancy
}

\author{
Eric P. Hamp \\ University of Chicago
}

Aspirates in combination with other aspirates, and their descendants, have had an enduring history of interesting developments throughout the course of prehistoric and historical Greek, up to the present day. The well-known facts concerning Grassmann's Law (aspirate dissimilation), as in $\tau \rho \varepsilon ́ \varphi-\omega$ "I nourish" from pre-Greek ${ }^{\star}$ threph-ō (from Proto-Indo-European (PIE) *dhrebh-) show this, as does the post-Classical manner dissimilation process that affected the voiceless fricatives (as continuations of the earlier voiceless aspirate stops of Ancient Greek), e.g. $\varphi \theta \alpha \dot{\alpha} v \omega>\varphi \tau \alpha \dot{\alpha} v \omega$, and persists in Modern Greek morpho-

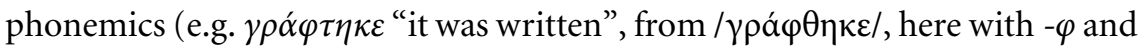
$\theta$-, and in mappings between one-time katharevousa forms still in current use and their dimotiki counterparts (e.g. $\chi \theta \varepsilon \varsigma \sim(\varepsilon) \chi \tau \varepsilon \varepsilon$ "yesterday").

Moreover, besides the well-known fact of PIE ${ }^{*}$ s yielding $/ \mathrm{h} /$ in certain environments in Ancient Greek (see below), there are also forms that some have seen as involving adventitious aspiration on a stop following ${ }^{*} \mathrm{~s}$ in $\sigma \varphi \alpha \rho \alpha \gamma \varepsilon$ ć $\mu \alpha \iota$ "burst with a noise" or $\sigma \varphi \alpha \lambda \alpha ́ \sigma \sigma \omega$ "cut, prick" (see Joseph 1985, and note - $\varphi$ following sigma). Interestingly, it seems that this connection has continued in a limited way in an altered form in the Modern Greek outcome of the ancient voiceless aspirates: in particular, the manner dissimilation noted above did not robustly affect all the post-Classical voiceless fricatives (from earlier voiceless aspirated stops) when they followed [s]. Even though $\sigma \theta$ and $\sigma \chi$ do regularly show dissimilation to $\sigma \tau / \sigma \kappa$ respectively, $\sigma \varphi$, for instance, shifted to $\sigma \pi$ only in a few dialects and not pan-Hellenically (see Thumb 1912:\$18). Thus in $\sigma \varphi$ the linkage between $s$ and a former aspirate remains. ${ }^{1}$

On the other hand, if we recognize that in this position the labial ${ }^{\star} \mathrm{p}$ seems to show a predilection for aspiration and that the spirant appears to resist a development to [-continuant], we then have a phonetic tendency in agreement 
with the known asymmetric loss of voiceless ${ }^{*} \mathrm{p}$ (see on this Hamp 1970 concerning labials in Mayan, and Hamp 1985 regarding the loss of ${ }^{*} p$ in Mongolian and Armenian; see also Hamp 1989).

The details of the chronology of developments involving aspirates and sibilance, either separately or in tandem, are, for prehistoric Greek, somewhat tricky to work out, but the following sequence of events now seems clear. This chronology, incidentally, has some consequences for the late Indo-European dialect grouping of Helleno-Armenian, what might be called "Pontic" (Hamp 1998:316-318).

In the course of reconstructing Greek $\dot{\varepsilon} \chi \dot{\varepsilon} \tau \lambda \eta$ "plough handle" and Welsh haeddel (fem.) < ${ }^{\star}$ sagedlā as PIE ${ }^{*}$ sg'hédhlā (i.e. ${ }^{\star}$ sg'h-é-dhl-eH $\left.\mathrm{a}_{\mathrm{a}} /-\mathrm{o}-\right)$ (Hamp 2003), as a result of which some modifications of detail in the reasoning of Hamp 1988-89 were made, a number of chronological stages in the phonological prehistory of Greek between PIE and Mycenaean time were discriminated.

1. PIE $^{\star}$ s (nearly) exactly as seen in Vedic (with Avestan; probably cuneiform Hittite), Lithuanian with Old Prussian, Gaulish (and Celtiberian?) with Ogam Irish, perhaps Messapic $>$ Helleno-Armenian ${ }^{\star} h$ (notably initially for many interests) except before obstruents or word-juncture and after obstruents or sonants. Initial ${ }^{\star}$ su $>{ }^{*}{ }^{*}$ hu developed as initial ${ }^{*}$ un devoiced, i.e. Armenian ${ }^{\star}{ }_{\hat{x}} />{ }^{*} \gamma^{\mathrm{w}} />{ }^{\star} \mathrm{g}^{\mathrm{w}} />{ }^{*} \mathrm{k}^{\mathrm{w}} \mathrm{h}>\mathrm{kh}$. Thus ${ }^{\star}$ seg'h- (Gk. ${ }^{\star}$ sek $-\mathrm{s} / \mathrm{t}-$,

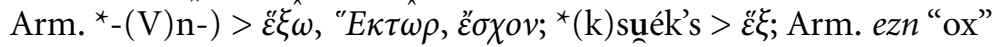

2. Devoicing of PIE aspirates in Greek, but not in Armenian

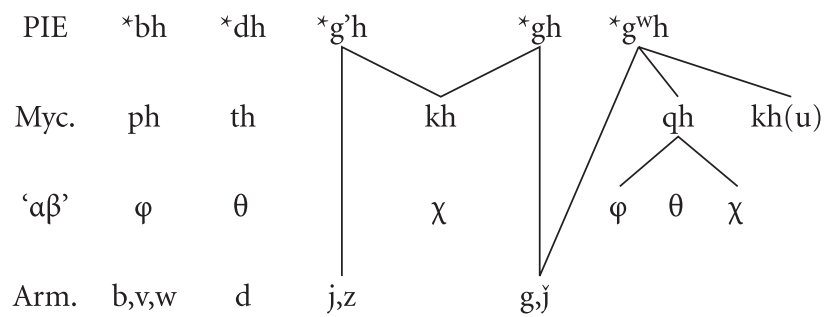

3. Suffix dissimilation (Meillet 1900:313, Hamp 1988-89:10-11), ${ }^{*}$ khú-thlo-n "liquid" > $\chi \dot{v} \tau \lambda o v(\dot{\varepsilon} \chi \dot{\varepsilon} \tau \lambda \eta$, etc.)

4. Fronting of medial $h$ (at the latest): ${ }^{\star}\left(\right.$ (?)'eusō $>$ Lat. $\bar{u} r \bar{o},{ }^{\star}$ euhō $>$ h'euō $\varepsilon \tilde{v} \omega$;

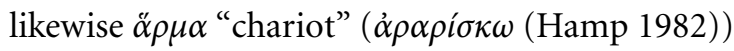

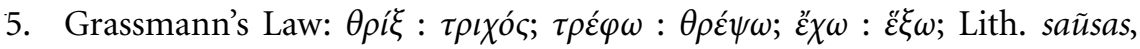
OCh.Slav suxz, sušiti, Srb-Cr. sûho, Eng. sear, Hell-Arm. ${ }^{\star}$ h'auhos $>$ Myc. *auhos 
6. Loss of medial (intervocalic) $-h-$. Post-Mycenaean ${ }^{*}$ auhos $>\alpha \tilde{v} o \varsigma$.

However, the language did not stop there, as it were, so it is useful to reflect on how some of the morphophonemic alternations that these changes created in early Greek have developed - in some instances being eliminated, in others being transformed - in later Greek, just as hinted at above with regard to some dissimilatory developments involving aspirates. In particular, some allomorphy vanished by way of regular sound changes, e.g. $\varepsilon^{\prime} \chi \omega / \tilde{\varepsilon}^{\prime} \xi \omega$ was altered by the loss of $/ \mathrm{h} /$ (as well as the loss of the synthetic future). In other cases, one alternant was generalized at the expense of the other, as with $\tau \rho \varepsilon \chi^{-} \omega$ "run" (where there is no trace in Modern Greek of the allomorph seen in the ancient future

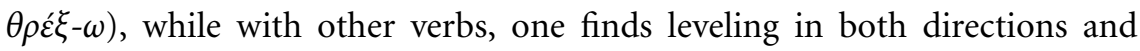

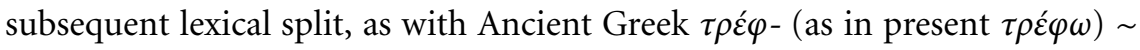
$\theta \rho \varepsilon \dot{\pi} \pi$ - (as in future $\theta \rho \varepsilon \dot{\psi} \psi \omega$ ) yielding Modern Greek $\tau \rho \varepsilon \dot{\varphi} \varphi \omega$ and $\theta \rho \varepsilon \dot{\varphi} \varphi \omega$ (the former possibly to be considered a learnedism). Some of these processes were under way in ancient times - note, for instance, that already in Ancient Greek, $\pi \varepsilon i \theta \omega$ "persuade" had only $\pi$-initial allomorphs, even when the conditions for Grassmann-induced alternations were met (thus future $\pi \varepsilon i \sigma \omega$, not ${ }^{* *} \varphi \varepsilon i \sigma \omega$, perhaps because ${ }^{\star} \theta \sigma$ words yield $-\sigma$-), and some of the suffixes possibly affected by suffix dissimilation were restored or applied analogically, so that, for instance, $\dot{\varepsilon}-\chi \dot{v}-\theta \eta v$ is found for presumed ${ }^{\star} \dot{\varepsilon}-\chi v^{\prime}-\tau \eta v$.

On the other hand, some phonotactic rules were broken by the occurrence of rule-governed phonetic change. So we find $\dot{\varepsilon} \pi \tau \dot{\alpha}>\varepsilon \varphi \tau \dot{\alpha}$, as well as $\varepsilon^{\prime} \varphi \theta \alpha \sigma \alpha>$ $\ddot{\varepsilon} \varphi \tau \alpha \sigma \alpha$.

Though unfolding over centuries and even millennia, recurring developments such as those mentioned here give credence to the view that despite changes that can both reinforce and undo old regularities the new patterns are just as rule-governed as the old; at the same time, these successions of fresh patterns call into question the bland assertion expressed e.g. by Browning (1983: vii) that "Greek is one language, not a series of distinct languages". If all Greek is one language, and not, for example, the same as Armenian, then we must be prepared to stipulate how we discern diachronically a language - or what else we should call it.

\section{Note}

1. Much more could be said about the developments with the manner dissimilation and especially the way in which borrowings from katharevousa have altered the historical 
distribution of the sounds; interestingly, it seems that restoration of the voiceless fricatives after $s$ (via spelling pronunciations or learned influence or the like) has proceeded in a less hindered fashion than after the other voiceless fricatives $\varphi$ and $\chi$. Of course, $s$ is the fricative par excellence inherited from Indo-European.

\section{References}

Browning, Robert. 1983. Medieval and Modern Greek. Cambridge: Cambridge University Press.

Hamp, Eric P. 1970. "Maya-Chipaya and Typology of Labials”. CLS 6.2-22.

Hamp, Eric P. 1982. “'Arm, Shoulder'”. Journal of Indo-European Studies 10:1-2.187-189.

Hamp, Eric P. 1985. “On Asymmetric Labial Loss and Armenian”. Journal of Turkish Studies 9.133-135. (Niguca Bicig: An Anniversary Volume in Honor of Francis Woodman Cleaves.)

Hamp, Eric P. 1988-89. “Thematic Nomina Instrumenti in Dental + Liquid”. Glossologia 7-8.7-11.

Hamp, Eric P. 1989. “The Indo-European obstruent features and phonotactic constraints”. The New Sound of Indo-European: Essays in Phonological Reconstruction (= Trends in Linguistics, Studies and Monographs, 41) ed. by Theo Vennemann, 209-214. Berlin \& New York: Mouton de Gruyter.

Hamp, Eric P. 1998. "Whose were the Tocharians? - Linguistic subgrouping and diagnostic idiosyncrasy". The Bronze Age and Early Iron Age Peoples of Eastern Central Asia (= JIES Monograph, 26) ed. by Victor H. Mair, vol. 1, 307-346. Washington, D.C.: Institute for the Study of Man.

Hamp, Eric P. 2003. "PIE *sg'hedhlā”. Münchener Studien zur Sprachwissenschaft, to appear. Joseph, Brian. 1985. "Proto-Indo-European Consonantism: Methodological and Further Typological Concerns”. Papers from the VIth International Conference on Historical Linguistics, Poznaön, 22-26 August 1983 ed. by Jacek Fisiak, 313-321. Amsterdam: John Benjamins.

Meillet, Antoine. 1900. "Sur les suffixes verbaux secondaires en indo-européen". Mélanges de la Société de Linguistique de Paris 11.297-323.

Thumb, Albert. 1912. Handbook of the Modern Greek Vernacular: Grammar, texts, glossary. Edinburgh: T.\&T. Clark. 